\title{
Upward Flame Spread and Critical Conditions for PE/PVC Cables in a Tray Configuration
}

\author{
M. A. DELICHATSIOS and M. M. DELICHATSIOS \\ Factory Mutual Research Corporation \\ 1151 Boston-Providence Turnpike, Norwood, Massachusetts 02062, USA
}

\begin{abstract}
We demonstrate how flame spread and fire growth can be predicted in a systematic way using a fire spread and growth (FSG) model developed at FMRC and small scale flammability measurements for PE/PVC cables in trays; this material pyrolyses in a more complicated way than a non-charring (e.g., PMMA) or a simple charring material (e.g., particle board). Similar methodology has been applied and validated for PMMA and various types of particle board. For PE/PVC cable trays, this procedure consists of the following parts: a) standard small scale flammability measurements (i.e., time to ignition, heat of combustion, product yields) and measurements of surface temperature histories and pyrolysis rates in a nitrogen atmosphere; b) a method to deduce from these small scale measurements "equivalent" material pyrolysis properties which can be inserted in a pyrolysis model to predict pyrolysis rates in fires; and c) the FSG fire spread model which uses the properties obtained in parts (a) and (b) for predicting fire growth and critical conditions for flame spread. The present work focuses on upward fire spread predictions and measurements for a specific $3 \mathrm{ft}$ high $\mathrm{PE} / \mathrm{PVC}$ cable tray.
\end{abstract}

KEYWORDS: Cable trays, flame spread, flammability

\section{INTRODUCTION}

One of the primary objectives in material flammability is the prediction of fire spread and growth for a given material in realistic fire situations for different geometric and environmental parameters. These parameters include configuration and size of the material, intensity and size of the ignition source and ambient conditions such as vitiation.

One of the most important inputs for fire growth predictions, such as predictions by the fire spread and growth (FSG) computer simulation model developed at FMRC, is the identification and measurement of material pyrolysis properties. A lot of effort and research has been devoted in this area (see Refs. 1, 2, 3, 4 and 10 for a more comprehensive bibliography). An outline of a methodology to obtain the required properties as well as application of this methodology to non-charring and charring materials ${ }^{(2,3,4)}$ has already been presented. 
In this work we extend this methodology to PE/PVC cables stacked in small trays. Cables are a more complicated material than a non-charring or simple charring material, because they consist of a jacket material, an insulation material, and the copper wires. Thus, they present a serious challenge to the cited methodology $(2,3,4)$. Other methods for cable flammability evaluation concern single cables ${ }^{(10)}$ (which are, indirectly, compared for ignition times in Fig. 1) or are single regulatory approval tests that are not discussed in this work.

The paper is structured in the following way: a) first we discuss how flammability properties of PE/PVC cables were obtained from small scale experiments, including surface temperature histories and pyrolysis rates in inert atmospheres in addition to the standard measurements of time to ignition and heat release rates; b) second, we describe upward flame spread experiments on a simulated PE/PVC cable tray; and c) finally, we compare predictions from an upward fire spread computer model (the FMRC FSG model) with the experiments; as inputs to the model, we used the properties measured in part a).

\section{SMALL SCALE FLAMMABILITY EXPERIMENTS AND MATERIAL PYROLYSIS PROPERTIES}

Small scale flammability experiments were run in the FMRC flammability apparatus ${ }^{(1)}$. In addition to standard measurements (i.e., time to ignition, pyrolysis and burning in ambient air), the following measurements were made in the FMRC apparatus:

1) Surface temperature histories by using a thermocouple attached to the surface; and

2) Pyrolysis rate histories for different imposed heat fluxes in a vitiated atmosphere $(10 \%$ $\mathrm{O}_{2}$ and $90 \% \mathrm{~N}_{2}$ ) where no burning occurs.

The same methodology was also applied earlier ${ }^{(2,3,4)}$ to non-charring (e.g. PMMA) and charring materials (e.g., particle board, wood) for obtaining material properties for flammability evaluation and flame spread and fire growth predictions.

The thermal response of a PE/PVC communication cable (11 mm outside diameter) prior to ignition is illustrated in Figures 1a and 1b. Figure 1a shows a plot of inverse square root

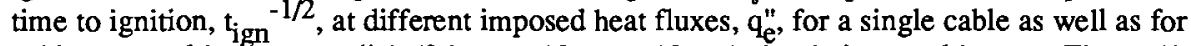
cables stacked in a square dish (2 layers, $10 \mathrm{~cm} \times 10 \mathrm{~cm}$ ) simulating a cable tray. Figure $1 \mathrm{~b}$ shows temperature histories at the surface of the cables and at the top of the bottom row for pyrolysis experiments at a vitiated atmosphere (10\% oxygen). The surface temperature is measured in two ways, by: a) spot melting the surface and attaching a thermocouple, and b) inserting a thermocouple in a shallow slit on the cable surface. The second method is also used to measure the temperature at the top of the bottom layer.

We point out some important observations from the results presented in Figures 1a and 1b: a) Both for single cables and cables in trays, the thermal response corresponds to a thermally thick situation because $t_{i g n}{ }^{-1 / 2}$ varies linearly with the imposed heat flux. For the present cables (11 mm outside diameter), the jacket is made of PVC (about $1 \mathrm{~mm}$ thick) and the insulation of the wires (about 100 wires) is made out of PE (polyethylene).

b) The response to ignition of single cables (see Figure 1a) is much faster than the response of cables closely stacked in a tray. There is reason to speculate that this difference ${ }^{(5)}$ is due to the surface configuration, which is convex for a single cable and both convex and concave for cables stacked in a tray. 


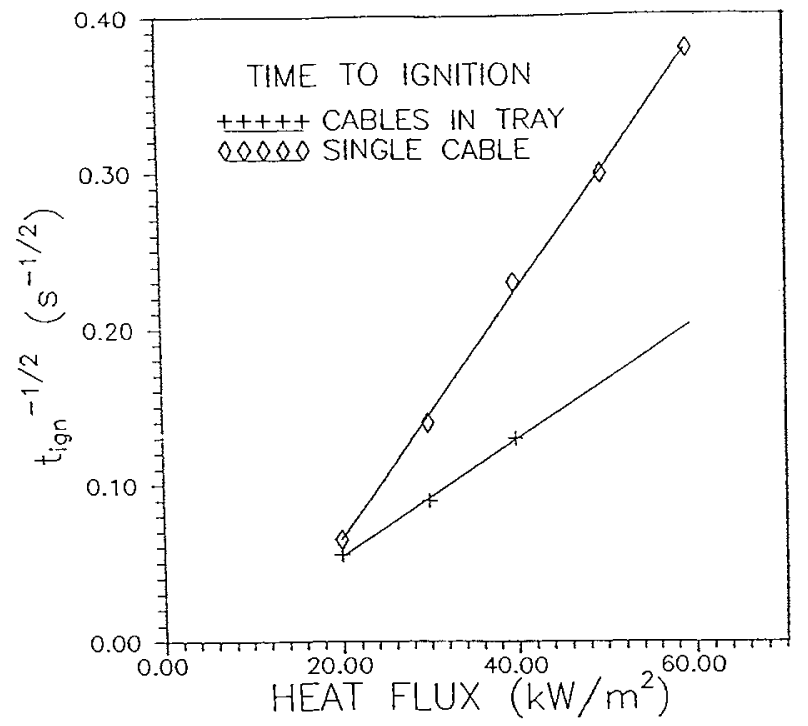

Figure 1a. Inverse square root of time to ignition versus imposed heat flux for single cables and two rows of cables stacked in a simulated cable tray.

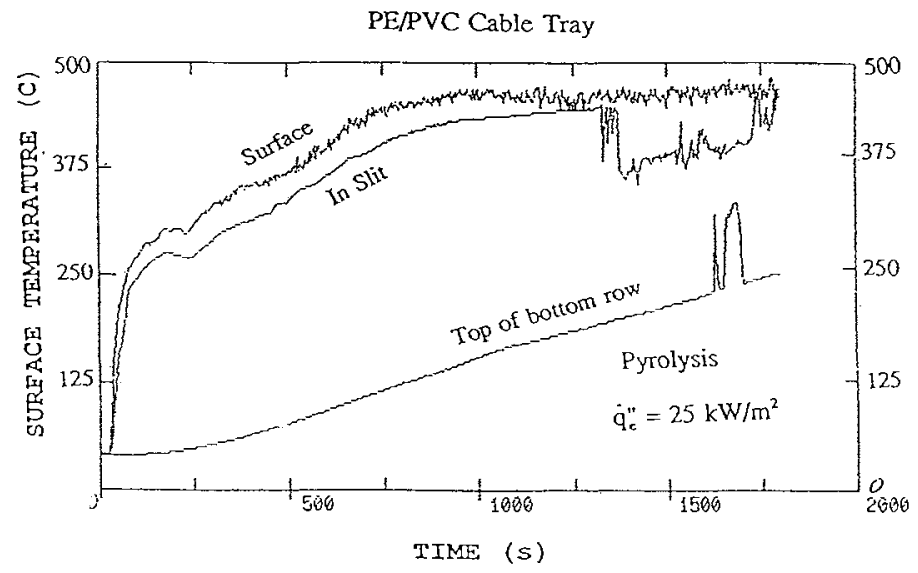

Figure 1b. Temperature histories for an imposed heat flux of $\dot{q}_{e}^{\prime \prime}=25 \mathrm{~kW} / \mathrm{m}^{2}$ in an inert atmosphere. Temperature is measured at the top of cables by two methods and at the top of the bottom row. 
c) The surface temperature history in Fig. $1 \mathrm{~b}$ indicates that PE/PVC cable pyrolysis can be characterized by two stages:

(1) as the surface temperature increases, there is a plateau at about $280^{\circ} \mathrm{C}$ where the chlorine is assumed to be released in the form of $\mathrm{HCl}^{(6)}$, and

(2) as the temperature reaches about $440^{\circ} \mathrm{C}$ the carbon compounds of $\mathrm{PVC}$ and $\mathrm{PE}$ are being pyrolyzed. A fraction (not quantified in these tests) of the PVC remains as char. These conclusions are supported by recent thermogravimetric experiments of mixtures of $\mathrm{PE}$ and $\mathrm{PVC}^{(6)}$, which also show that about $10 \%$ of the PVC mass remains as char. The transition from the first stage to the second stage becomes faster and more difficult to distinguish as the imposed heat flux increases. ${ }^{(6)}$

The observations for the thermal response of PE/PVC allows us to notice that heat-up and ignition can be approximated by a heat transfer model ${ }^{(4)}$ : The slope of the "cable tray" line in Figure 1a is equal to:

$$
\frac{2}{\sqrt{\pi} \sqrt{k \rho c} \Delta T_{p}}=.004
$$

and the abscissa intercept, $9 \mathrm{~kW} / \mathrm{m}^{2}$, is equal to about $64 \%$ of the critical heat flux, $.64 \dot{\mathrm{q}}_{\mathrm{cr}}^{\prime \prime}{ }^{(7)}$ (For an imposed heat flux below the critical heat flux no ignition occurs.) Here, $k, \rho, c$, are effective thermal properties, $T_{p}-T_{o}=\Delta T_{p}$ is the pyrolysis-ignition temperature rise over the initial temperature.

The following values for the properties have been estimated: $\mathrm{T}_{\mathrm{p}}=700^{\circ} \mathrm{K}\left(\dot{\mathrm{q}}_{\mathrm{cr}}^{\prime \prime}=\sigma \mathrm{T}_{\mathrm{p}}^{4}=13\right.$ $\left.\mathrm{kW} / \mathrm{m}^{2}\right), \mathrm{k \rho c}=0.5\left(\mathrm{~kW} / \mathrm{m}^{2}\right)^{2} \mathrm{~s} / \mathrm{K}^{2}$ from Figure 1a. We notice that the estimated value of the pyrolysis temperature $\left(700^{\circ} \mathrm{K}\right)$ represents the second stage of the pyrolysis process for the $\mathrm{PE} / \mathrm{PVC}$ cables as is shown in Fig, 1b. Notice also, that the estimated value for $\mathrm{kpc}$ represents an equivalent property for the cables, which consist of a mixture of PVC, PE and copper.

Accepting these thermal property values as adequate for predicting time to (piloted) ignition by using a heat transfer model, the next issue is how to represent the mass pyrolysis rate of the PE/PVC cables. Two types of experiments were done in the FMRC apparatus for cables in a tray set-up, first in a vitiated atmosphere without burning, and then in ambient atmosphere, including burning. Some results and correlations are shown in Figures $2 \mathrm{a}$ and $2 b$, which plot mass loss histories for a series of heat fluxes in a reduced or ambient air atmosphere. Measurements were also performed for the heat release rate ${ }^{(1)}$ when burning occurred.

One can observe from Figures $2 a$ and $2 b$ that mass pyrolysis rate increases to a steady pyrolysis rate, and then it decreases until pyrolysis stops owing to flammable material burnout and formation of a thin char layer. The second layer of cables is not completely pyrolyzed for any imposed heat flux. From the steady state period, at each of three imposed heat fluxes, one can calculate both the effective heat of gasification, $\Delta \mathrm{H}_{\mathrm{v}}=2,500 \mathrm{~kJ} / \mathrm{kg}$, and the actual heat of combustion, $\Delta \mathrm{H}_{\mathrm{c}}=12,000 \mathrm{~kJ} / \mathrm{kg}$ (note that the exposed area of cables is $.0077 \mathrm{~m}^{2}$ ).

For modeling purposes, however, as in the FSG model, one also needs to reproduce the transient pyrolysis rate as measured in Figure $2 \mathrm{a}$. The pyrolysis process for the present case, as it was discussed with regard to surface temperature histories, involves at least two 
Figure 2a. Mass loss histories in a simulated $10 \mathrm{~cm} \times 10 \mathrm{~cm}$ cable tray for different imposed heat fluxes in an inert atmosphere (no burning) or in ambient air (including piloted ignition).

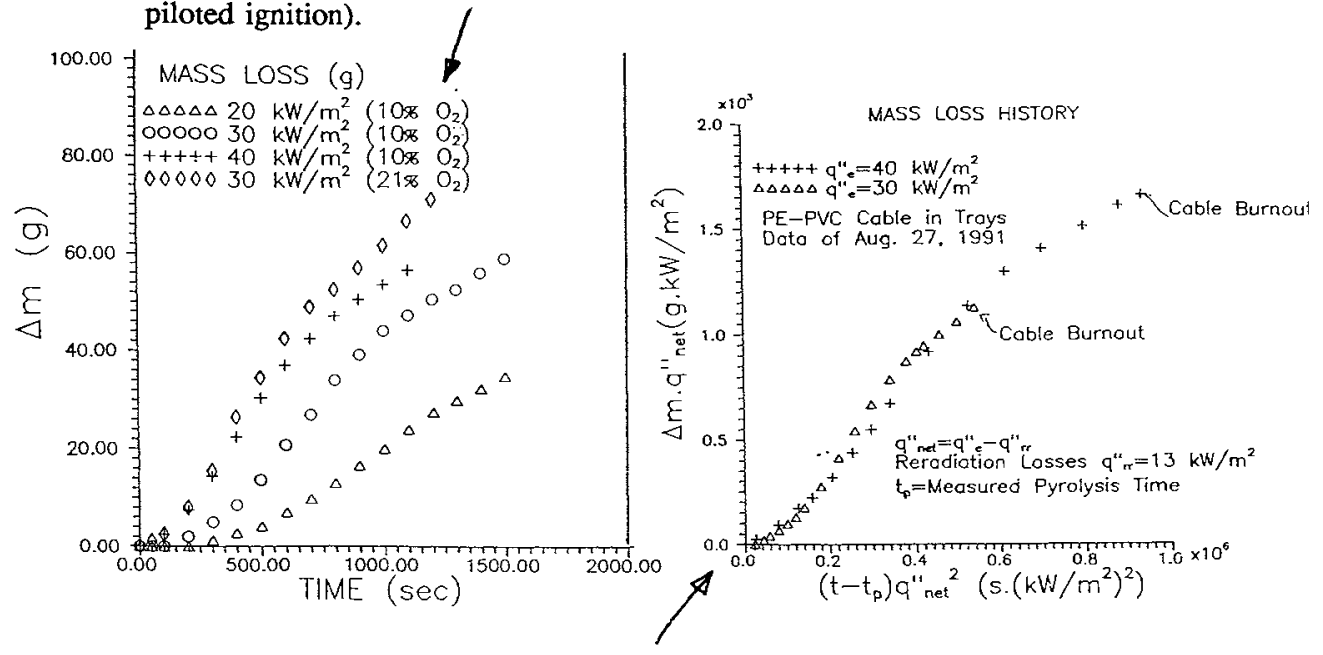

Figure 2b. Correlation of mass pyrolysis histories (shown in Fig. 2a) by using coordinates consistent with a non-charring pyrolysis model.

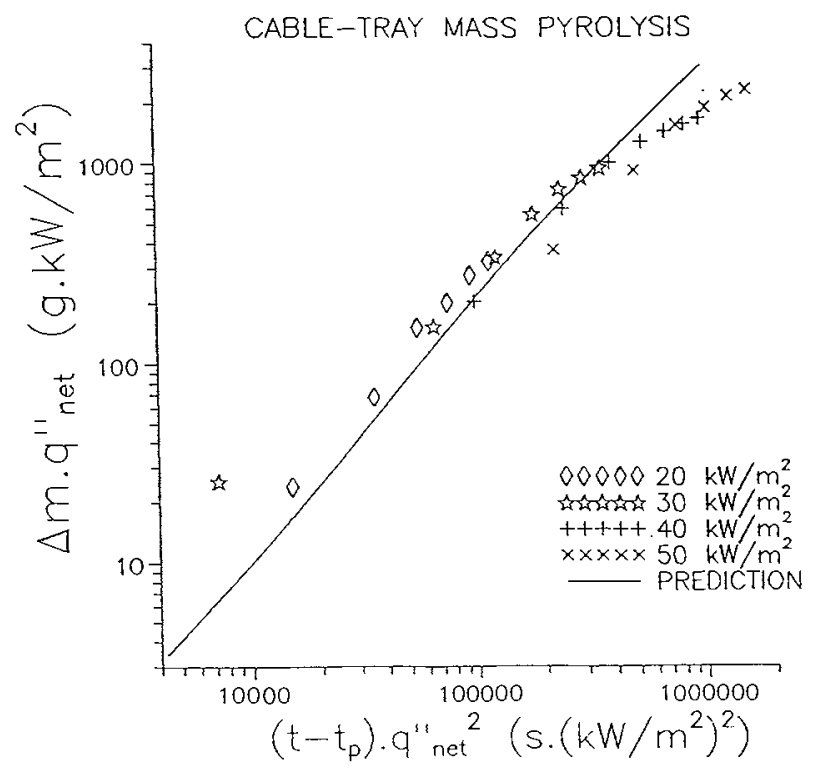

Figure 2c. Prediction of mass pyrolysis histories (see Fig. $2 a$ and $2 b$ ) by using properties deduced from Fig. 2a and a non-charring pyrolysis model. Near the end of pyrolysis the non-charring model is not applicable. 
pyrolysis stages at temperatures $280^{\circ} \mathrm{C}$ and $430^{\circ} \mathrm{C}$, as shown in Figure $1 \mathrm{~b}$. It is difficult to describe this process because not enough information can be obtained for modeling the two pyrolysis stages by using only the present flammability apparatus. Instead, we have attempted, as shown in Figure $2 b$, to reproduce and model the mass loss histories by assuming that they would be represented by a non-charring thermal pyrolysis model having a single pyrolysis (= ignition) temperature equal to $\mathrm{T}_{\mathrm{p}}=700^{\circ} \mathrm{K}\left(427^{\circ} \mathrm{C}\right)$. For a non-charring material, we have shown before ${ }^{(7)}$ that mass loss histories should correlate as:

$$
\Delta m \dot{q}_{\text {net }}^{\prime \prime}=f c n\left[\left(t-t_{p}\right) \dot{q}_{\text {net }}^{\prime \prime 2}\right]
$$

where

$$
\dot{q}_{\text {net }}^{\prime \prime}=\dot{q}_{e}^{\prime \prime}-\dot{q}_{c r}^{\prime \prime}=\dot{q}_{e}^{\prime \prime}-\sigma T_{p}^{4}
$$

and $t_{p}$ is the pyrolysis (= ignition time). For the present plot in Figure $2 b$, the pyrolysis time (= ignition time) is taken for consistency to be the same as measured in Figure 1a; this time can also be calculated, consistently, by using the equivalent properties $\mathrm{T}_{\mathrm{p}}=700^{\circ} \mathrm{C}, \mathrm{k \rho c}=$ $0.5\left(\mathrm{~kW} / \mathrm{m}^{2}\right)^{2} \mathrm{~s} / \mathrm{K}^{2}$.

We may conclude from Figure $2 b$, that the mass loss history for the PE/PVC cables may be represented by a non-charring pyrolysis model which should be modified to include a reduction in the pyrolysis rate at later times. Measurements have shown that burnout occurs when a fixed amount of PE/PVC flammable material is consumed, $(\Delta \mathrm{m})_{\max }=6 \mathrm{~kg} / \mathrm{m}^{2}$, which is nearly independent of the imposed heat flux. We propose to approximate the mass loss history by using a) a non-charring thermal pyrolysis model up to a time when the mass pyrolysis is equal to $70 \%$ of $(\Delta \mathrm{m})_{\max }$, i.e., $4.2 \mathrm{~kg} / \mathrm{m}^{2}$, and b) subsequently, the pyrolysis rate decreases to $2 \mathrm{~g} / \mathrm{m}^{2}$ s until the total mass pyrolyzed is $6 \mathrm{~kg} / \mathrm{m}^{2}$.

To complete the determination of the non-charring pyrolysis model, one must determine the value of the equivalent latent heat of gasification, L. Note that the effective heat of gasification, $\Delta \mathrm{H}_{\mathrm{v}}=\mathrm{L}+\mathrm{c} \Delta \mathrm{T}_{\mathrm{p}}$, has already been determined from the steady state pyrolysis rate in Figure $2 \mathrm{a}, \Delta \mathrm{H}_{\mathrm{v}}=2,500 \mathrm{~kJ} / \mathrm{kg}$, The latent heat of gasification which affects the transient initial growth of mass loss history is estimated in the following way ${ }^{(8)}$ :

a) First, find the intercept of the steady state pyrolysis rate with the time axis, e.g. for heat flux $30 \mathrm{~kW} / \mathrm{m}^{2}$, the intercept is $\mathrm{t}_{\mathrm{i}}=300 \mathrm{~s}$, as shown in Fig. 2a,

b) Second, find the ratio $\left(t_{i}-t_{p}\right) / t_{p}$ which for heat flux $30 \mathrm{~kW} / \mathrm{m}^{2}$ is

$$
\frac{t_{i}-t_{p}}{t_{p}}=\frac{300-175}{175}=.714
$$

c) this ratio is equal to ${ }^{(8)}$ :

$$
0.714=\frac{4}{\pi} \frac{\Delta H_{v}}{c \Delta T_{p}}-1
$$

from which one obtains 


$$
\frac{\Delta H_{v}}{c \Delta T_{p}}=1.35
$$

Thus, one can obtain from Eq. (2c) the equivalent value for the specific heat by noticing that $\Delta \mathrm{T}_{\mathrm{p}}=700-293=407^{\circ} \mathrm{K}, \Delta \mathrm{H}_{\mathrm{v}}=2,500 \mathrm{~kJ} / \mathrm{kg}$. This value is equal to:

$\mathrm{c}=4.55 \mathrm{~kJ} / \mathrm{kg} \mathrm{K}$

One can also find an equivalent property value for the thermal conductivity $\mathrm{k}$ by using the value of density $\rho=1,500 \mathrm{~kg} / \mathrm{m}^{3}$ in the measured value of $\mathrm{k \rho c}=.5\left(\mathrm{~kW} / \mathrm{m}^{2}\right)^{2} / \mathrm{K}^{2}$.

$$
\begin{aligned}
& \mathrm{k}_{\text {equ }}=7.32 \times 10^{-5} \mathrm{~kW} / \mathrm{m}^{0} \mathrm{~K} \\
& \rho_{\text {equ }}=1,500 \mathrm{~kg} / \mathrm{m}^{3} \\
& c_{\text {equ }}=4.55 \mathrm{~kJ} / \mathrm{kg}^{0} \mathrm{~K}
\end{aligned}
$$

The high value for the equivalent specific heat $\left(4.55 \mathrm{~kJ} / \mathrm{kg}^{0} \mathrm{~K}\right)$ may be attributed to represent the latent heat absorbed during the first stage of pyrolysis (see Fig. 1b) which is not directly modeled by the present methodology. We should emphasize that although these values do not necessarily represent any actual properties for the complicated system of PE/PVC cables, they can be used together with a simple heat transfer and a thermal pyrolysis non-charring model to predict the time to ignition and the mass pyrolysis rates for PE/PVC cables, as is demonstrated in Figure $2 \mathrm{c}$ for various imposed heat fluxes in an inert atmosphere.

\section{UPWARD FLAME SPREAD EXPERIMENTS ON SIMULATED CABLE TRAYS}

Upward flame spread experiments on a PE/PVC cable were conducted on a cable tray shown in Fig. 3. The tray was made of aluminum $0.20 \mathrm{~m}$ wide by $0.05 \mathrm{~m}$ deep by $0.91 \mathrm{~m}$ long. Two layers of PE/PVC cables (11 mm 0D) were placed on the tray (fourteen cables on each layer). The aluminum tray was covered with $3.2 \mathrm{~mm}$ thick insulation on its sides and its back. Ten thermocouples were attached on the surface along a cable at the centerline of the cable tray. Most thermocouples were attached on the surface of the cable. In some cases, thermocouples were placed into a cut $.5 \mathrm{~mm}$ under the surface of the cable.

Upward flame spread experiments were run in the FMRC flammability apparatus. In the experiments, the quartz heaters of the apparatus provided a $40 \mathrm{~kW} / \mathrm{m}^{2}$ ignition source. The ignition source was located $.15 \mathrm{~m}$ from the bottom of the tray and was extended over the whole width of the tray $(0.20 \mathrm{~m}$ wide $)$ and over a height approximately $.10 \mathrm{~m}$. Heat release rates and surface temperature histories are shown in Figures $4 \mathrm{a}$ and $4 \mathrm{~b}$. After initial preheating, the area exposed to the imposed heat flux ignites and produces a high heat release rate $(-4.8 \mathrm{~kW})$, which is followed by a decrease to a level of about $1 \mathrm{~kW}$, corresponding to a decreased rate of pyrolysis of the ignition zone owing to cable burnout of the exposed surface area and/or partial charring. During this period, the flames of the ignition zone preheat upper parts of the cable tray, which in turn starts pyrolyzing 200 seconds later. The heat release rate increases, and at 700 to 800 seconds it starts decreasing again. It is worthwhile to note that the total fire spread (pyrolysis zone) in this experiment is equal to 


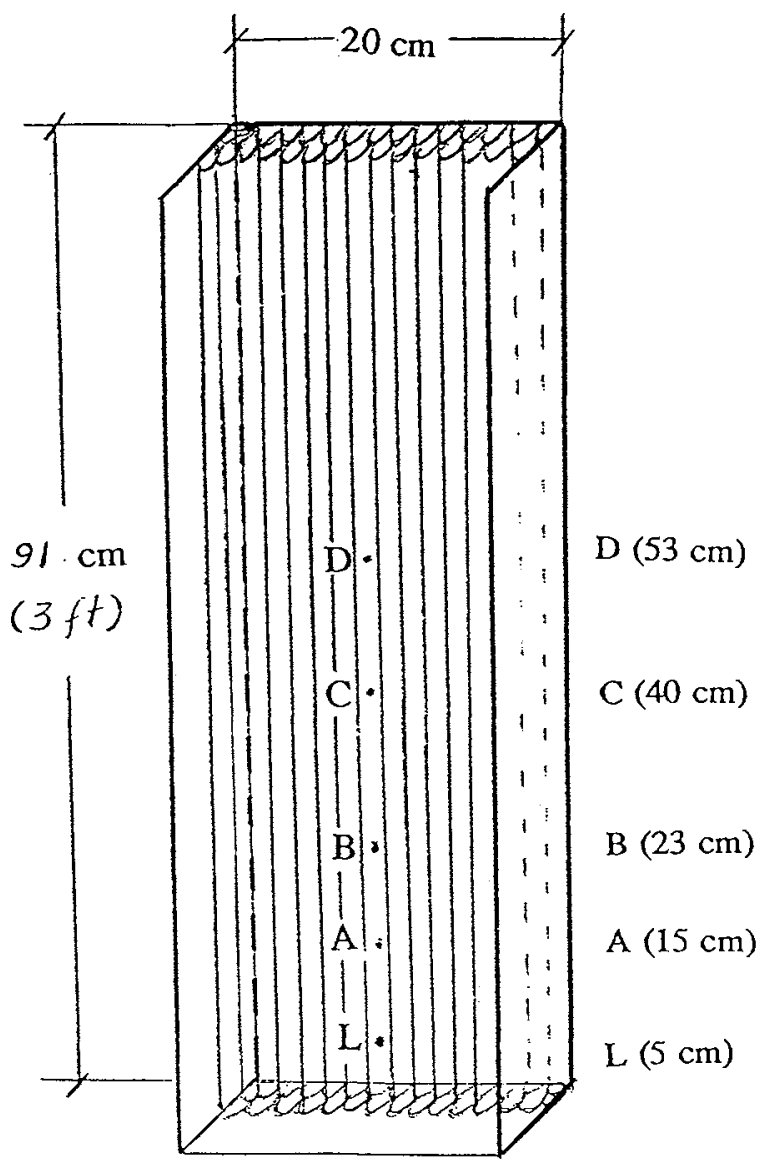

Figure 3. Schematic of the simulated cable tray for upward flame spread experiments including thermocouple locations. A heat flux of $40 \mathrm{~kW} / \mathrm{m}^{2}$ is imposed over about $10 \mathrm{~cm}$ (from location $A$ to $B$ ) across the tray. 
$.60 \mathrm{~m}$ from the bottom of the tray, or equal to $.45 \mathrm{~m}$ from the bottom of the ignition source. Thermocouple histories (Fig. 4b) corroborate these observations.

\section{MODEL PREDICTIONS AND CRITICAL CONDITIONS FOR FLAME SPREAD}

The experimental results in Figure $4 a$ and visual observations for flame spread can be compared with predictions in Figures $5 \mathrm{a}$ and $5 \mathrm{~b}$. Predictions have been made by using the flammability properties for a PE/PVC cable obtained in a previous section, together with the FSG model developed earlier at FMRC. ${ }^{(9)}$ A uniform flame heat flux of $25 \mathrm{~kW} / \mathrm{m}^{2}$ is used over the whole flame length. ${ }^{(9)}$ This model has been validated for upward flame spread on non-charring and charring materials.

By comparing the heat release rates Fig. $4 \mathrm{a}$ (measured) and Figure 5a (predicted), one can see that the agreement is good considering the complexity of this material. Maximum values, the shape and characteristic times agree well between predictions and experiment. The sharp drop of the heat release rate in the predictions (Fig. 5a), which differ from the experimental behavior (Fig. 4a), are attributed to the approximation of the mass pyrolysis rate histories; these histories were approximated near the burnout to drop suddenly to a value of $2 \mathrm{~g} / \mathrm{m}^{2} \mathrm{~s}$ (see section on material properties).

Finally, Figure $5 \mathrm{~b}$ shows that the maximum length of the pyrolysis is about $.47 \mathrm{~m}$, which is in remarkable agreement with the experimental observations. The sudden increase in the pyrolysis length is attributed to the uniform flame heat flux assumed over the whole flame length. One should also note that the maximum length occurs much earlier than the second sharp drop of heat release rate (cf with Fig. 5a), a fact which is also consistent with visual observations.

As a final remark, it is important to emphasize that the predicted maximum flame spread length, as shown in Figure $5 \mathrm{~b}$, agrees with the value obtained by similarity analysis for spread on non-charring materials ${ }^{(2)}$ :

$$
\ell_{m}=1.4 \times 10^{-4}\left(\dot{q}_{n e t}^{\prime \prime} \frac{\Delta H_{c}}{\Delta H_{v}}\right)^{2}=0.47 \mathrm{~m}
$$

where the cable properties represented earlier were used. This estimate is applicable for a single cable tray, where a) ignition occurs near its base; and b) the only heat flux to the cables is imposed by its own flames having a value of $\dot{q}_{n e t}^{\prime \prime}=\dot{q}_{f}^{\prime \prime}-\dot{q}_{r r}^{\prime \prime}$ estimated to be equal to $25-13=12 \mathrm{kw} / \mathrm{m}^{2}$.

\section{CONCLUSIONS}

The main conclusions of this work are:

1. It is possible to find "equivalent" flammability properties for a PE/PVC cable in a tray, to characterize its ignition and burning if, in addition to standard measurements, surface temperature and pyrolysis histories are measured in an inert atmosphere (Figs. 1a, 2a, 2b, 2c). 


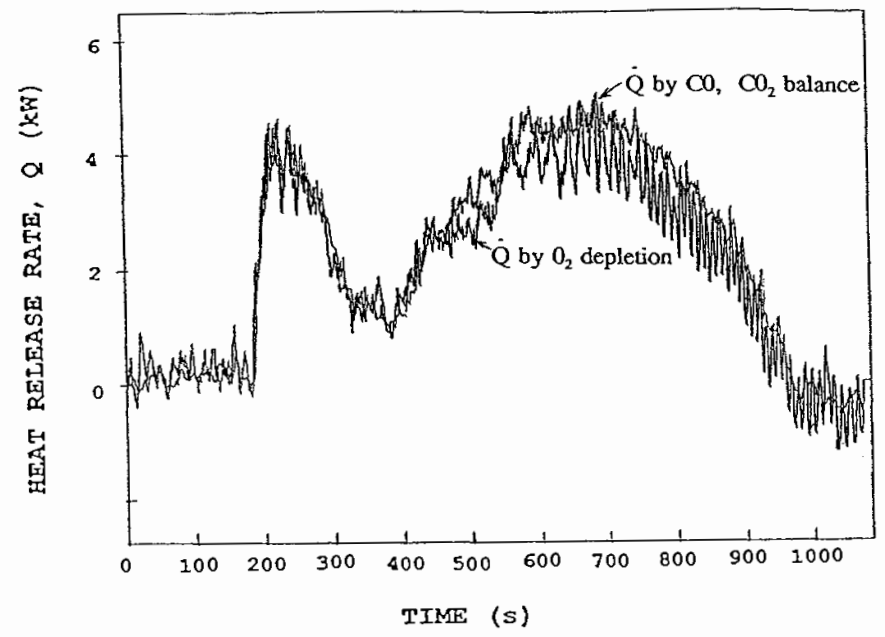

Figure 4a. Heat release rate histories for a flame spread experiment on the cable tray shown in Fig. 3 for an imposed heat flux $40 \mathrm{kw} / \mathrm{m}^{2}$ over about $10 \mathrm{~cm}$ near its base.

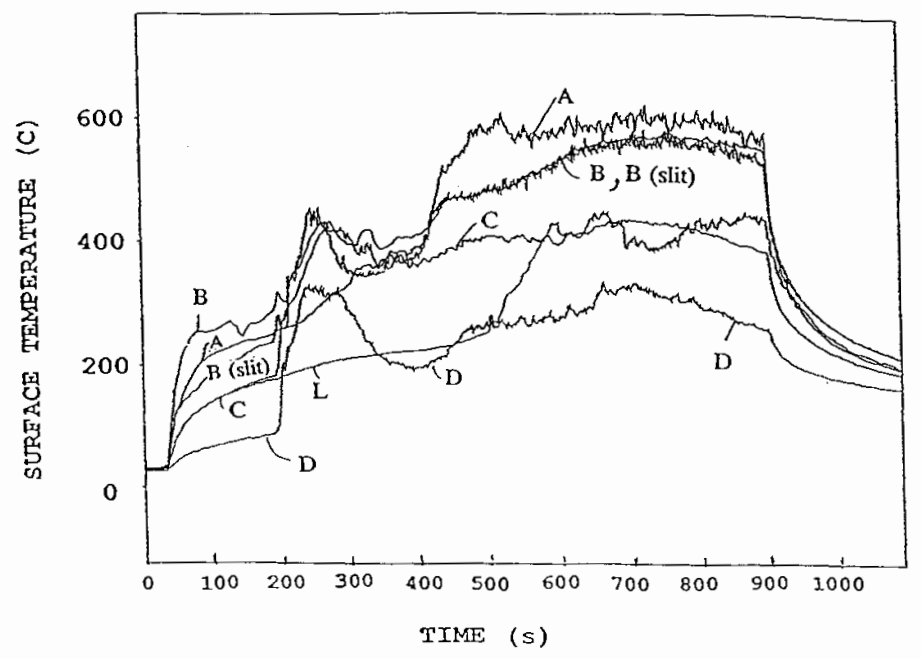

Figure 4b. Surface temperature histories for the same experiment as in Fig. 4a; symbols characterize the thermocouples as shown in Figure 3. 


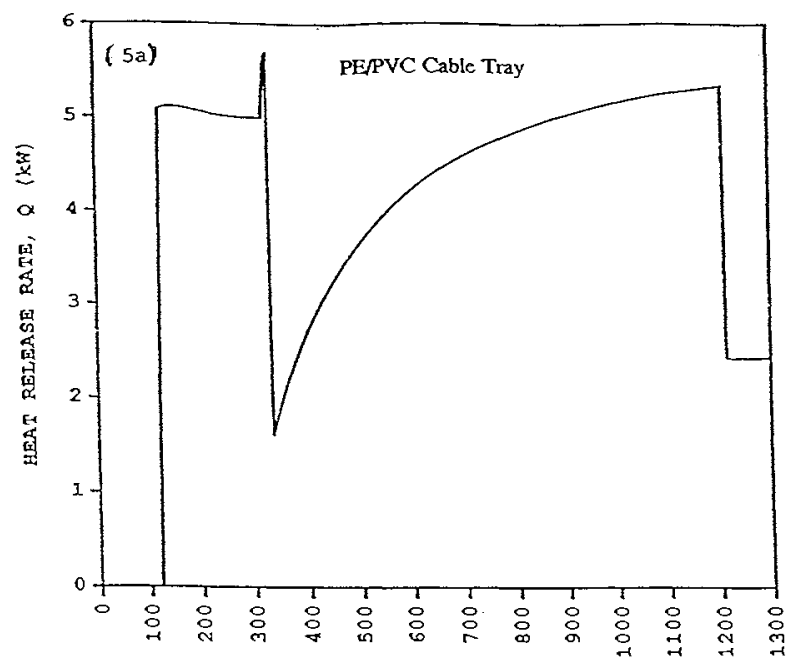

Figure 5a, Prediction of upward flame spread experiment corresponding to the data in Figure $5 \mathrm{~b}$ Figures $4 \mathrm{a}$ and $4 \mathrm{~b}$. Figure $5 \mathrm{a}$ plots the predicted heat release rate history, which compares well with the data in Figure 4a. Figure $5 b$ plots the location of the pyrolysis front vs. time. The pyrolysis front reaches a maximum height of about $.47 \mathrm{~m}$, which is also consistent with the experimental visual observations.

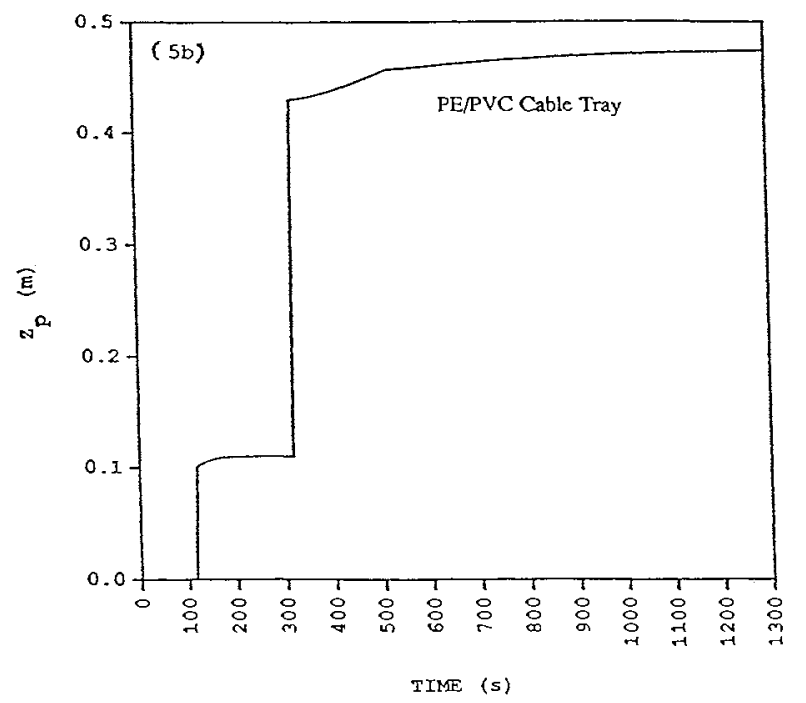


2. Using these properties and the FMRC FSG model, upward fire spread and fire growth on a $3 \mathrm{ft}$ high PE/PVC cable tray can be adequately predicted (Figs. 4a, 5a, 5b); in addition, critical conditions and a maximum flame spread length can also be evaluated for the $3 \mathrm{ft}$ high $\mathrm{PE} / \mathrm{PVC}$ cable tray by using the expression in Eq. (4).

\section{ACKNOWLEDGEMENTS}

We would like to thank Mr. S.D. Ogden for helping with the experiments.

\section{REFERENCES}

1. Tewarson, A. and Khan, M.M., "Flame Propagation for Polymers in Cylindrical Configuration and Vertical Orientation," Twenty-Second Symposium (International) on Combustion, Pittsburgh, PA: The Combustion Institute, 1988, pp. 1231-1240.

2. Delichatsios, M.A., Chen, Y., Delichatsios, M.M., and Hasemi, Y., "Similarity Solutions for Upward and Wind Assisted Flame Spread and Applications to NonCharring Materials such as PMMA," ASME Winter Meeting, Anaheim, CA, 1992.

3. Delichatsios, M.A. and Saito, K., Proceedings of the Third International Symposium of Fire Safety Science, pp. 217-226, Elsevier, NY, 1991.

4. Delichatsios, M.A., Journal of Fire Sciences, pp. 287-295, 1993.

5. Chen, Y., Motevalli, V., and Delichatsios, M.A., "Development of an Integral Model for Prediction of Flame Spread on Horizontal Surfaces," Central and Eastern State Sections, The Combustion Institute, p. 626, March 15-17, 1993.

6. Bockhorn, H., and Knumann, R., "Investigation of the Kinetics of Pyrolysis of PVC by TG-MS-Analysis," submitted to Comb. Science and Technology, 1993.

7. Delichatsios, M.A., Panagiotou, T., and Kiley, F., Combustion and Flame, 84, pp. 323-332, 1991.

8. Delichatsios, M.A. and Chen, Y., Combustion and Flame, 92, 292-307, 1993.

9. Delichatsios, M.M., Mathews, M.K., and Delichatsios, M.A., "An Upward Fire Spread and Growth Simulation," Proceedings of the Third International Symposium of Fire Safety Science, pp. 207-216, Elsevier, NY, 1991.

10. Fernandez-Pello, A.C., Hasegawa, H.K., Staggs, K., Lipsika-Quinn, A.E. and Alvares, N.J., "A Study of the Fire Performance of Electrical Cables," Proceedings of the Third International Symposium on Fire Safety Science, pp 237-247, Elsevier, NY, 1991. 